\title{
POSTPRINT
}

\section{Instruction practices in German driving lessons: Differential uses of declaratives and imperatives}

\section{Arnulf Deppermann}

\author{
Institut für Deutsche Sprache, PF 101621, \\ Mannheim, Germany \\ Correspondence: \\ Arnulf Deppermann, Institut für Deutsche Sprache, \\ PF 101621, 68016 Mannheim, Germany. \\ Email: deppermann@ids-mannheim.de
}

\begin{abstract}
Building on a corpus of 70 hours of German driving lessons, this paper studies the use of declaratives vs. imperatives for instruction. It shows how these linguistic resources are adapted to different praxeological, temporal and participant-related environments. Declaratives are used for first instructions, task-setting and posttrial discussions. They exhibit complex syntax and do not call for immediate compliance. Their high degree of explicitness conveys how the action is to be carried out. Imperative instructions overwhelmingly correct ongoing actions of students or respond to their failure to produce expected actions. They exhibit minimal argument structure. They are reminders which presuppose that the student monitors the scene and can perform the action unproblematically. They index that requests have to be complied with immediately or even urgently.
\end{abstract}

\section{Keywords:}

conversation analysis, declarative, German, imperative, Instruction

Auf Basis eines Korpus von 70 Stunden Videoaufnahmen praktischer Fahrschulstunden wird der Gebrauch von Deklarativen und Imperativen in Instruktionshandlungen untersucht. Es wird gezeigt, wie die Verwendung dieser grammatischen Ressourcen an praxeologische, zeitliche und interaktionsgeschichtliche Bedingungen angepasst wird. Deklarative werden für Erstinstruktionen sowie zur Setzung komplexer Fahraufgaben und in Nachbesprechungen verwendet. Sie zeichnen sich durch komplexe Syntax aus und fordern keine unmittelbare Befolgung. Sie fokussieren, wie eine Handlung auszuführen ist. Imperative werden dagegen vornehmlich zur Korrektur laufender Fahrhandlungen (in Reaktion auf Fehler und auf ausbleibende Handlungen) eingesetzt. Sie zeichnen sich durch minimale Argumentstrukturen aus. Sie fungieren als Erinnerungen an korrektes Fahren und setzen voraus, dass der Schüler die fragliche Handlung problemlos produzieren kann. Imperativische Instruktionen zielen auf unmittelbare oder gar dringliche Befolgung ab.

\section{Schlüsselwörter:}

Instruktion, Konversationsanalyse, Imperativ, Deklarativsatz, Fahrschule 


\section{INTRODUCTION}

The most important pedagogical activity in driving lessons are instructions. Still, as linguistic research on talk and interaction in driving school is still very rare (but see Broth, Cromdal, \& Levin, 2017; De Stefani \& Gazin, 2014; Deppermann, 2015), little is known about the precise ways in which language is used to adapt to this site of instruction. This paper argues that grammar is used as a resource which is both sensitive to the process of learning and to the temporal contingencies of the instructed action. This will be shown by analyzing the use of the two most frequent linguistic formats in driving lessons in German: declaratives and imperatives. Section 2 describes sequential, tempo-spatial and participant-related properties of instructions in driving lessons. In section 3 , the corpus of the study is presented, together with an overview of the linguistic formats of instructions encountered in the data. The main body of the paper deals with instructional uses of declaratives (section 4) as opposed to imperatives (section 5). Section 6 summarizes the main results.

\section{INSTRUCTIONS IN DRIVING LESSONS}

Mondada (2014: 133-134) and Lindwall, Lymer, and Greiffenhagen (2015: 144-145) distinguish between 'instructions' as pedagogic activity, as actions designed to get a recipient to do something, and as written texts (like a manual). The first two properties apply to instructions in driving school: They are pedagogically designed and ask the recipient to comply. For the largest part, driving lessons consist of instructional sequences (section 3). As De Stefani and Gazin (2014) have pointed out, instructions can concern navigation (directions, landmarks, speed, etc.; see also De Stefani this volume) or the use of car controls (gears, mirrors, instruments, etc.). A third major class of instructions concerns issues of (visual, cognitive) attention.

Instructions can be produced before task-rehearsals, as first, descriptive explanations of how to perform a task (subsection 4.1) or after rehearsals in the context of post-trial discussions (subsection 4.3). Most instructions, however, are part of task-performances (subsection 4.2), which are usually organized according to this sequential pattern (Deppermann, 2015: 75, adapted from De Stefani \& Gazin, 2014): ${ }^{1}$

1. INS: task-setting instruction;

2. STU: driving response;

3. INS: corrective instruction;

4. STU: driving response;

5. repeat $2-4$ until task completion; and

6. INS: final assessment and post-trial discussion of task-performance.

Tasks are rehearsed repeatedly and often with a high frequency. The car's behavior is a direct proof whether a relevant skill has been learnt and whether the student responds adequately to an instruction.

Instructions in driving lessons are sensitive to the specific ecology of the setting. Driving must take spatial, temporal and physical-technical constraints into account, which is reflected by the design of instructions. Since the car and other traffic participants are continuously in motion, the spatial relationship between them and relevant 
landmarks also constantly changes (De Stefani this volume), sometimes in unanticipated ways. Correct handling of the car is also necessary for safety reasons. For all these reasons, actions are often time-critical and urgent (cf. Mondada, 2017 , this volume).

Driving lessons exhibit a specific activity-related and spatial participation framework, which is consequential for instructional practice. Participants are involved in multiple activities, which have to be coordinated simultaneously or consecutively (Mondada, 2012): driving, monitoring traffic, talking with each other (and sometimes also communicating with other traffic participants). They are seated side-by-side (cf. Kendon, 1990: 213) and focus on the road and the traffic, therefore attention to each other and visual perception are limited. The pedagogic relationship between the participants is highly asymmetric: Concerning the driving tasks and the required skills, the instructor is both epistemically and, therefore, deontically in the superior position. ${ }^{2}$ Although the student stays in the inferior epistemic position, it is precisely the trajectory from a novice to a competent member (cf. Goodwin, 2017), and that is, from somebody lacking knowledge to somebody with sufficient knowledge for relevant task-performances, which characterizes the process of learning. As we will see in sections 4 and 5 , the evolution of the student's competence over time is reflected by the linguistic resources used for instructions at various stages of the learning process (Deppermann, forthcoming).

Instructions are produced for the ultimate benefit of the student, i.e. to advance their learning process. While instructions often are formulated as directives (cf. Craven \& Potter, 2010) and requests (cf. Drew \& Couper-Kuhlen, 2014), they can also be produced as explanations or descriptions. Driving lessons being a pedagogical setting, most instructions in this context are designed to convey transferrable knowledge. Their aim is not just to make the student perform a certain action once, but to help the student to acquire the skill to perform the action autonomously whenever it becomes relevant in the future.

\section{GRAMMATICAL FORMATS OF INSTRUCTIONS IN GERMAN}

This study builds on a corpus of 70 hours of driving school lessons in German with two instructors (1 male, 1 female) and nine students ( 6 male, 3 female). Lessons were recorded with two cameras (street view and passenger view) and an additional audio recorder. Instructions are by far the most frequent verbal actions in driving school. Instructed tasks are highly recurrent, for example, to change gears, to park the car, to reverse the car, to turn left or right at an intersection. 180 minutes of driving lessons (approx. 90 minutes with each instructor) were exhaustively coded for the grammatical realization of instructions. Each single instruction, realized by a turn, a TCU or part of a TCU, was counted separately. In total, $N=1,721$ instructions were found, meaning that instructors produce an instruction every six seconds on average.

Instructions are realized by a great number of different grammatical formats. The following formats could be found in the corpus:

1. All declarative formats together account for $n=489$ instances $(28.4 \%)$.

a. The most frequent are present tense indicative declaratives ( $=358,20.8 \%$ ): du biegst links ab ("now you turn left"); for all declaratives, 2nd person singular and 1st person plural may be used. Although instructed actions lie in the future, future tense does not occur.

b. Modal verb declaratives ( $n=128,7.4 \%$ ): du musst/kannst/darfst nicht links abbiegen ("now you must/can/ may not turn left"); the deontic verbs müssen ("must"), sollen ("should"), können ("can"), dürfen ("may") are used in affirmative and negative variants, wollen ("want") only in the affirmative and brauchen ("need") only in the negative variant.

c. Future subjunctive ( $n=3,0.2 \%$ ): ich würde links abbiegen ("I would turn left"): this form uses the subjunctive of the auxiliary verb werden and occurs only with the 1st person singular; it corresponds to the English conditional II. 
2. Imperatives ( $n=349,20.3 \%$ ): bieg links ab ("turn left"); only the morphological imperative (2nd person singular) without subject is used in the corpus; the "polite" clausal imperative with 2 nd person plural subject does not occur.

3. Deontic ("free") infinitives ( $n=348,20.2 \%$ ): links abbiegen ("to turn left"): this format has no subject (in the corpus) and no infinitive particle zu (cf. Deppermann, 2006, 2007).

4. Noun phrases ( $n=50,2.9 \%$ ): nächste Straße (links) ("next street (to the left)"): Noun phrases encode objects or landmarks of the instructed action.

5. Bare nouns ( $n=115,6.7 \%$ ): Kupplung ("clutch"): These encode objects or landmarks of the instructed action, but may also be nominalizations of actions (e.g. Schulterblick, "shoulder check").

6. Directive prepositional phrases ( $n=59,3.4 \%$ ): jetzt nach links ("now to the left"): These are used for navigational instructions.

7. Adjectives/adverbs ( $n=125,7.3 \%$ ): links, noch etwas weiter ("left", "still a bit further"): These refer to locative, directional, temporal or manner aspects of the instructed action.

8. Other verb-less ellipses ( $n=197,11.4 \%$ ): da vorne noch mehr ("there still more (of this)"), nächste Ausfahrt raus ("next exit out"): Like the latter example, such ellipses often consist of an object NP and a verb particle ( $n=48$, $2.8 \%)$.

9. Discourse particles ( $n=13,0.8 \%$ ): gut, so, nein ("okay", "alright", "no"): A small range of discourse particles is used to require the student to begin or to stop an action.

10. Questions ( $=7,0.4 \%$ ): biegst du links $a b$ ? ("do you turn left?"): Questions are very rarely used for instruction; neither subjunctives nor modal verbs are used.

Gestures also play an important role in instructions (see Deppermann, 2016; Mondada this volume). Pointing, knocking, snipping fingers and gazing, but also direct interventions into the driving process (braking or grasping the steering wheel) are used for instructions, together with talk or free-standing. The coding, however, only takes verbal instructions into account. The following analysis focuses on the two most frequent syntactic types, declaratives and imperatives.

\section{DECLARATIVES}

In pragmatic accounts of the illocutionary force of sentence types, declaratives are treated as assertions by default (Searle, 1979). Still, it has been recognized early that declaratives may be used for requesting. First, a declarative can contain a description of the requested action (in present or, very rarely in German, in future tense). Second, the declarative can formulate the requested action via a modal verb construction with 1st person wollen ("want") or 2nd or 3rd person müssen ("must"), sollen ("should"), können ("can") or nicht dürfen ("may not"). Third, indirect requests (see Searle, 1979) are produced by uttering a statement (e.g. the counter-factual, ironic observation "the pedestrian is now dead again"), which, given the current situation and taking Gricean maxims into account, is meant to ask the addressee for some action which the state of affairs described makes relevant ("look back when reverse parking the car"; see Rauniomaa this volume). All three uses of declaratives for instructing actions occur in the corpus of driving lessons under study, however, not for the same kind of instructions. Since modal and indirect declarative instructions are rarer, we will restrict the analysis to the first variety, i.e. declaratives which state requested actions. This sort of declaratives occupies three different positions within instructional sequences:

1. first instructions (4.1);

2. task-setting instructions (4.2); and

3. post-trial instructions (4.3) 


\subsection{Declaratives in first instructions}

When a procedure or skill to be learnt is explained to the student for the first time, instructions are always delivered in a declarative format. In extract 1, the instructor explains how to reverse park the car. She uses two toy cars (one representing the driving school car, the other a parked car) in order to demonstrate the procedure.

Extract 1 FAHR_02_15_32:01-32:23

01 INS isch erklär dir jetzt mal kurz das einparken, I now briefly explain to you the parking

02

$(0.4)$

$03 \mathrm{STU} \mathrm{hm} \mathrm{hm}$. uhum

04 INS anhand unsers kleines autochens, = with our little toy car

$05=$ das geht dann nämich immer ganz gut; this works then always quite well

06 (1.6)

07 INS $0>$ ah hat sogar die selbe farbe ja.<0 (it) has even the same color yes

08 STU ((short laugh))

09 INS Oh <A: : IsO;> (0.6) alright

10 du stehst jetzt hier so_n meter nebendran; = you stand.2SG now here like-one meter next-at-there you stand about one meter next to the other

11 =siehst_zte? you see?

ins ...... ofpoints at toy car--->

12 STU hm_hm, uhum

13 INS oh wichtig is, das auto muss gra:de stehen; important is the car must.3SG straight stand.INF It is important that the car must stand straight

14 und die räder müssen grạ:de sein-r and the wheels must.3PL straight be.inf and the wheels must be straight

ins $>$ 웅

15 INS alles schön ogra: :de. everything nicely straight

ins .......... ofpoints ahead to front window----------->

$16[80] \$.

okay

ins $---\rightarrow>$ 웅

17 STU [hn_] ja, yes

18 INs ohh dann, (0.4) ffährst du gra::de zurück, o then drive.2SG you straight back then you drive back straight oreverses toy car------------o

19 \% $(0.3)$

ins spoints at B-column of driving school car---> 


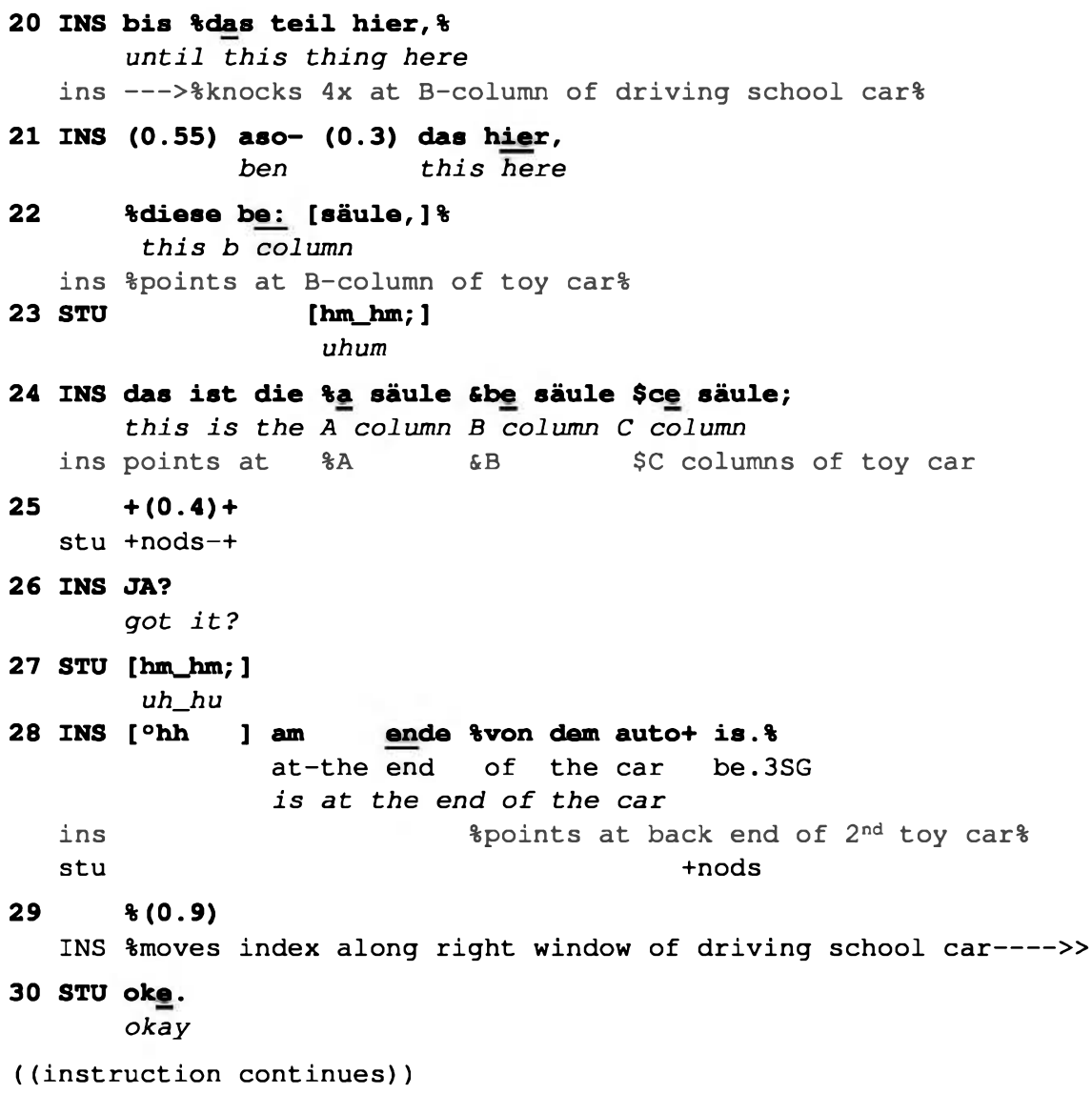

This lengthy, multi-unit turn instruction contains an explanation of the canonical steps of the procedure of reverse parking. The driving school car is not moved during the whole instruction and the individual steps of the instruction are not to be followed in situ. The student is only expected to monitor closely the instructor's explanation and her demonstration by using a toy car (cf. the tags in lines 11 and 26). Her instructional turns (lines 10, 13-15, 18-28) all contain declarative sentences. They formulate or imply actions to be performed by the student driver, except for line 24 , in which the instructor explains the technical term be säule ("B column"). Two of the instructions are modal declaratives (lines 13-14), describing that the car has to be positioned straight before starting the procedure. An additional analeptic statement (alles schön grade, "everything nicely straight", line 15) building on these two instructions is used here to yield a three-part list (cf. Jefferson, 1990). Each instructional sentence exhibits at least two arguments. In addition to the agent (the driver), or, in lines 13-14, the patient (the car, the wheels), locative, directional and manner arguments are formulated. The locative argument of the instructional sentence in lines 18-28 is realized by an adverbial clause (lines 20/28). This part of the instructor's turn is particularly complex: after a double referential self-repair (lines 21-22), the explanation of the term be säule is inserted parenthetically.

Declaratives which are used for instructing in later trials, after some skill has already been instructed at least once, do also occur sometimes. However, their design is much leaner: they are shorter, exhibit less arguments and use more pronominal and deictic arguments instead of full lexical NPs.

\subsection{Declaratives in task-setting instructions}

Task-setting instructions are instructions in which a complex task is formulated which requires the execution of a series of coordinated actions (Deppermann, 2015). While the task-setting instruction sets the goal, the individual 
actions to be performed are not spelt out. Task-setting instructions are navigational instructions (like "we turn left at the next intersection," "now you change to the overtaking lane") in the sense of De Stefani and Gazin (2014). They are overwhelmingly formulated by declaratives. In contrast, instructions which correct the student's ongoing task-performance are formulated by other grammatical formats. Extract 2 shows a task-setting instruction (line 01) and the consecutive corrective instructions (lines $02-10$ ) the instructor produces in response to failures of the student's taskperformance.

Extract 2 FOLK 146 0:34-1:00

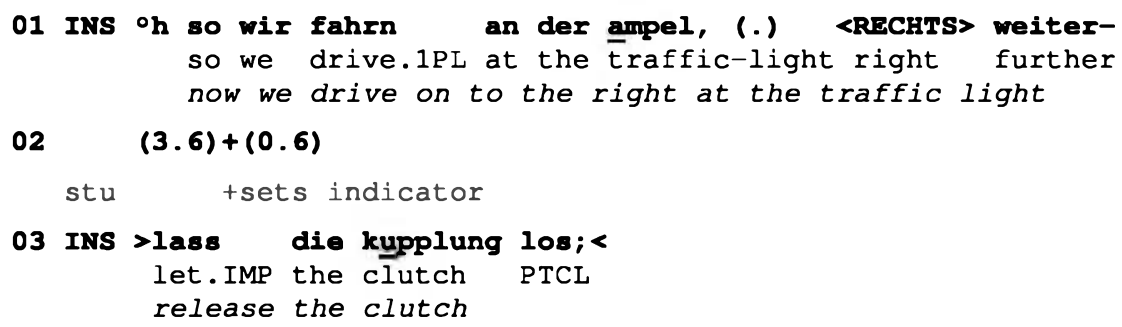

04 (6.9)

05 INs \&gabriel, (.) gu (0.3) cken; name look.INF Gabriel look

ins ofinger-snip

06 (4.5)

07 INS <vorau: schau-> anticipation. $\mathrm{N}$ anticipation

08 \& (0.2) \&innen, inside.ADV inside

ins 8 .... ofpoints at interior mirror

09 INS $\&(0.3)$ zausen,

outside.ADV

outside

ins $\frac{\circ}{6}$....

(0.9)

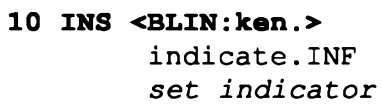

11

(0.3)+

stu +sets indicator

The task-setting instruction (so wir fahrn an der ampel, (.) <RECHTS $>$ weiter, line 01 ) is formulated by a 1 st person plural present tense declarative. The instructed action cannot be carried out immediately. It is only the endpoint of a series of well-coordinated driving actions which the student should perform autonomously in order to be able to comply with the instruction in the way the instructor expects her to (cf. Deppermann, 2015). Some of these actions are made explicit by subsequent corrective instructions (Lindwall \& Ekström, 2012, see subsection 5.1), which respond to failures on the part of the student or which anticipate that the student will not perform the required actions at the right moment or in the right way: The student is asked to let the clutch go (line 03), to look back in order to check whether there are pedestrians or cyclists following (line 05 - the finger-snip signals the 
direction), to anticipate the behavior of other traffic participants (line 07) by looking into the inner and the right side-mirror of the car (line 08) and finally to set the indicator to the right (line 10). In contrast to the task-setting instruction, which is a navigational instruction, these corrective instructions are car control instructions (De Stefani \& Gazin, 2014) and requests for monitoring the traffic. For these corrective instructions, various grammatical formats are used, which are not used for task-setting instructions: an imperative (line 03), deontic infinitives (lines 05 and 10), a bare noun (line 07), and adverbs (lines 08, 09). While the task-setting declarative includes a rich argument structure with three arguments (agent "we," locative "at the traffic light", directional argument "to the right"), the corrective instructions exhibit much leaner syntax and reduced argument structure. Only the instruction to let the clutch go (line 03) encodes an object; all others mention only the action (lines 05, 07, 10 by a nominalized verb), or they are verb-less, mentioning only the relevant direction in which the object to be used (the mirror) is located (lines 08, 09).

The higher degree of explicitness of the task-setting declaratives (and thus the greater complexity of their syntax and argument structure) is motivated by the fact that the instruction does not respond to and does not build on actions, events and objects which can be taken to be undoubtedly salient to both parties. Instead, the instruction establishes a new joint, not-yet-projected or already-to-be-expected project with a new goal. Therefore, action, landmark and direction have to be overtly expressed in order to avoid ambiguity or confusion. The use of the declarative as such, in contrast to imperatives, deontic infinitives and various verb-less elliptical formats, seems to index that the instructed action should not be performed immediately. (Section 5 will show that imperatives call for an immediate response.) Requesting a non-immediate response, declaratives are very apt for mandating complex tasks which require an extended trajectory of actions to be fulfilled until the mandated action can be completed. In contrast, the other grammatical formats are more apt for mandating simpler actions, which should be performed immediately and which can be, because they are of a simpler, "one-step" kind.

\subsection{Declaratives in post-trial instructions}

When a task has been completed, the student's performance is assessed by the instructor. The assessment may extend to a post-trial discussion, in which causes for failures, alternative ways of coming to terms with the task, the relevance of situated conditions for task-performance, etc. are dealt with. A regular part of post-trial discussions are instructions designed to help the student to improve their future performance. Extract 3 begins with instructions while the student steers the car out of the parking lot (lines 01-02). He does not manage to position the car as close to the car to the right as is required in order to repeat the procedure of reverse parking. The instructor now initiates a post-trial discussion (lines 03-12).

Extract 3 FAHR_02_09_31:01-31:20

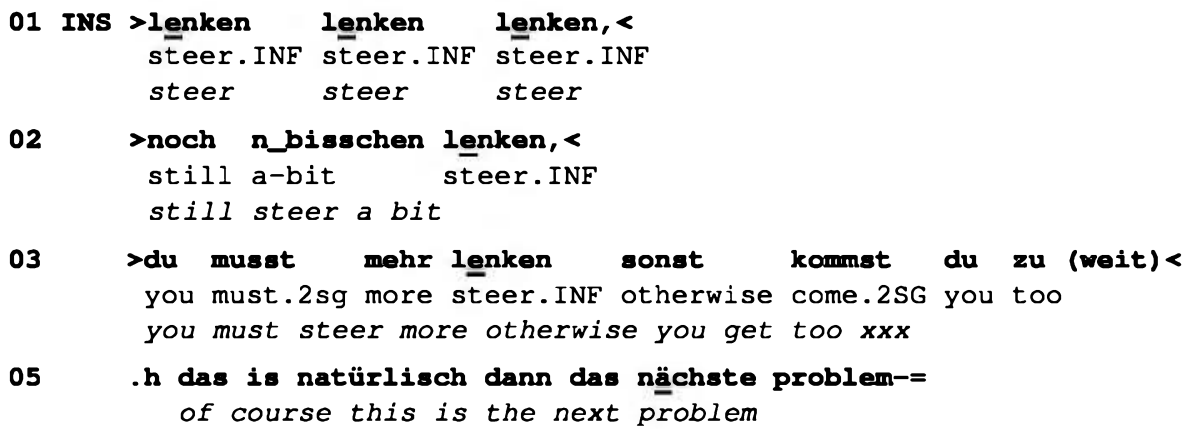




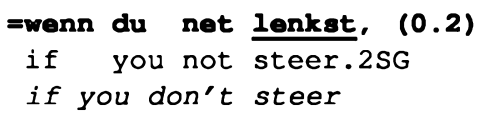

07

dann hast du natürlisch kein abstand von nem meter hier then have.2SG you of-course no distance of one meter here then of course you don't have a distance of one meter here

08 sondern das sind dann halt anderthalb;

but these are then PTCL one-and-a-half

but this is one and a half then

09

.h und is jetzt net so tra;gisch,

and this is no big deal now

10

aber das musst du natürlisch mit einreschnen

but this must.2SG you of-course with take-into-account.INF

but of course you must take this into account

11

twenn du in die parklücke reinfährst;
if you in the gap drive-into.2SG
if you drive into the gap
tnods---------------

12 INS dass du (.) mehr platz hast;

that you more space have.2SG

that you have more space

13

(0.9)

14 STU ja?

right?

While the student is still driving, the instructor produces instructions which correct on the student's ongoing driving actions. The instructions lenken, lenken lenken noch $n_{-}$bisschen lenken (lines 01-02), meaning that the student should continue to turn the steering wheel, are formulated as deontic infinitives without any arguments. Their very lean format makes imperatives apt for instructions projecting immediate compliance. As the student has positioned the car next to a car to his right, the instructor argues how the student has to steer in order to get into the correct position, which is closer to the other car (lines $03 \mathrm{ff}$ ). In the post-trial discussion, instructions are not formulated by infinitives as before, but by modal declaratives (lines 03 and 10-12; cf. also Mondada, 2013), and they are to be understood as rule formulations holding in general. The instruction in line 03 du musst mehr lenken sonst kommst du zu ("you have to steer more otherwise you will get too") should not be followed in situ, but formulates a deontic rule and accounts for it by stating an unwanted consequence of not complying with the rule. The instruction is produced by a complex sentence including a (cut-off) adversative adverbial clause. The second post-trial instruction aber das musst du natürlisch mit einreschnen wenn $d u$ in die parklücke reinfährst dass du mehr platz hast ("but of course you have to take into account if you enter the gap that you have more space," lines 10-12) is also a complex modal declarative, which includes both a conditional adverbial and a complement clause. It is an argumentative conclusion, which builds on the conditional and adversative relationship between driving actions and their spatial effects stated in line 07-09. It is also formulated by a complex sentence involving two adverbial clauses.

Post-trial instructions formulate and build on causal, conditional, temporal, adversative, concessive and antithetic relationships between driving actions and temporal, spatial, mobile, traffic-participant-related and other conditions and effects. They are always formulated as declaratives, often using complex adverbial patterns. Arguments (apart from references to the student driver) are overwhelmingly lexically encoded (instead of being pronominalized) and actions are explicitly formulated (and not omitted), because the instruction does not respond to ongoing or 
immediately preceding actions, but refers to objects, places, etc., which are either not present or not unambiguously salient in the current situation.

\section{IMPERATIVES}

Prior research has highlighted differences in the use of imperatives for requesting in contrast with other request formats, which are also pertinent to our study. In contrast to the declaratives discussed in section 4 , imperatives in the driving school corpus always require immediate compliance (cf. Vine, 2009: now-imperatives): They call for immediate, and sometimes even urgent, bodily responses (Mondada, 2013, 2014, this volume). It has also been noted that imperative turns tend to be short (Mondada, 2013, 2017): they are morphologically and, what is more, syntactically shorter than declarative or interrogative requests (Rossi, 2012, 2015). Mostly no or only one (object or directional) argument is encoded and arguments are preferentially pronominal (and not lexical, see Zinken \& Deppermann, 2017). Imperatives have been found to be used in certain action environments:

- to correct on prior faults or ongoing faulty actions of the addressee (Antaki \& Kent, 2012; Mondada, 2013; Vine, 2009);

- to insist on prior directives (Craven \& Potter, 2010; Goodwin, 2006; Goodwin \& Cekaite, 2013); and

- to request actions which contribute to a line of action to which the requestee has already committed him/herself before or which s/he has even already started (Rossi, 2012; Zinken \& Deppermann, 2017; Zinken \& Ogiermann, 2013).

Other conditions for the use of imperatives concern participant-related properties. Prior research has related the use of imperatives to asymmetries in power (Blum-Kulka, House, \& Kasper, 1989; Brown \& Levinson, 1987), high entitlement (Craven \& Potter, 2010) and asymmetries of knowledge (Antaki \& Kent, 2012; Mondada, 2013), the producer of the imperative being in the deontically and/or epistemically superior position. A somewhat competing line of research, however, stresses that often it is not so much asymmetry between participants, but rather shared responsibility and orientation to a joint project (Rossi, 2012; Zinken \& Deppermann, 2017; Zinken \& Ogiermann, 2013) which accounts for the use of imperatives. In the case of imperatives in driving school, both aspects can be seen to converge: There is a clear epistemic and deontic asymmetry between instructor and student, who, however, work on a joint institutional project.

In driving lessons, imperatives are used in various sequential and turn-constructional environments. The two most distinctive environments will be analyzed in detail:

- corrective interventions (5.1) and

- insisting turns (5.2)

\subsection{Corrective interventions}

The overwhelming number of imperatives is used to correct on an ongoing action of the student driver or to mandate an action which the instructor expects the student to initiate autonomously without instruction, but which has not been performed by the student yet. Both uses of imperatives are responsive in being occasioned by the current "faulty" driving behavior of the student, i.e. by its discrepancy to instructor's expectations of correct driving. In this 
way, imperatives build on continuous monitoring of the student's driving actions and they are precision-timed with respect to the precise details of the student's current (non-)activity and to emergent driving requirements which are not (yet) adequately dealt with by the student (cf. Lindwall \& Ekström, 2012). Extract 4 provides an example. The student was told to reverse the car. He tries to comply with this request by entering the next driveway in order to turn around (cf. the analysis in Deppermann, 2015, subsection 6.1). As the student starts to turn towards the driveway, the instructor brakes (line 01) and then produces an imperative asking the student to pay attention (line 02) to his following account and instruction to drive on (lines 04-06). As the student hesitantly moves on with low speed, the instructor repeats four times his instruction to speed up using imperatives (lines 11, 12, 14, 16).

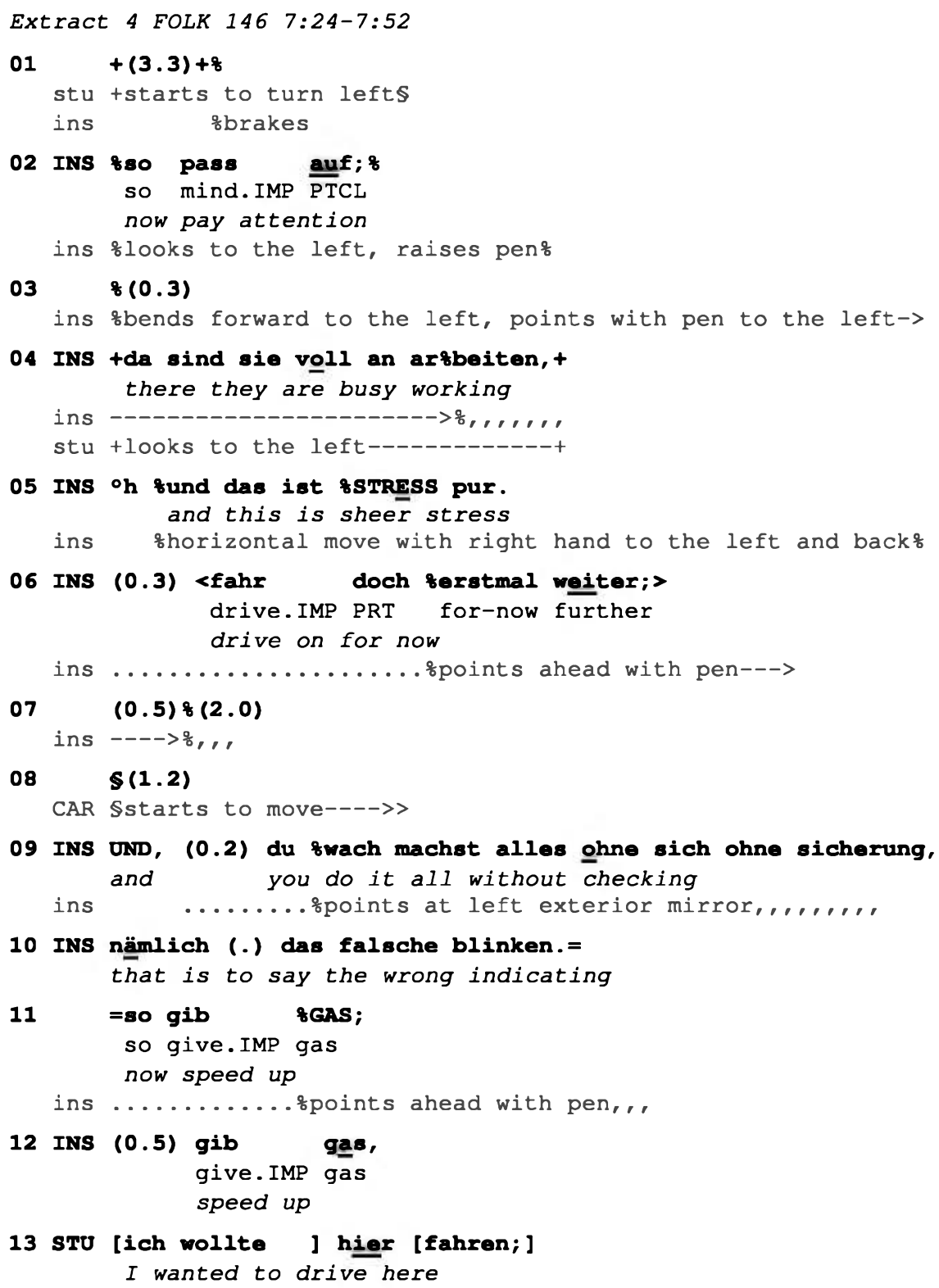




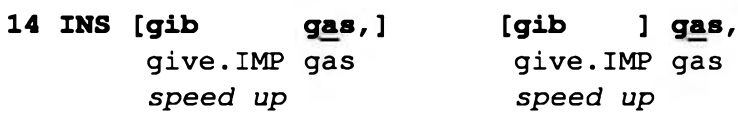

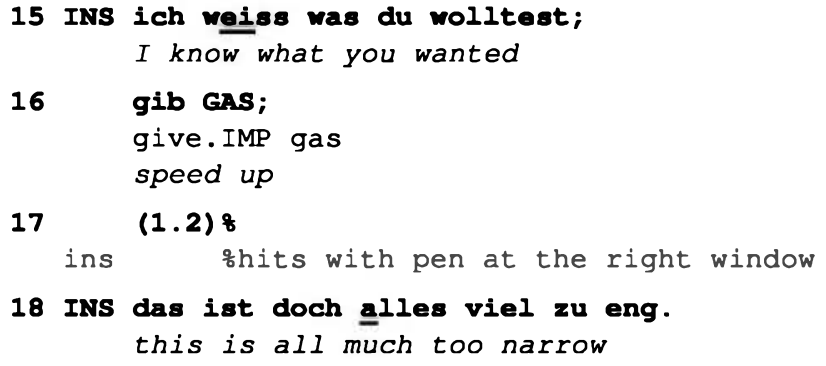

The request to pay attention (line 02) does not make any response relevant by itself, but highlights the relevance of the upcoming corrective instruction to drive on (line 06). Both actions are produced as imperatives. They respond to the student's visible attempt to reverse the car at a point which the instructor considers not to be suitable, because of the presence of construction workers (see line 04). The following five imperative instructions to speed up (lines 11-16) are again corrective and deal with the student's resistance to comply. They respond to the low speed the student takes and reject the student's attempt at explaining his driving intentions in line 13, insisting instead on the lingering relevance of the instructor's request. These imperative clauses do not exhibit arguments. ${ }^{3}$ Only in line 06 , a temporal adjunct (erstmal, "for now") is added.

While in extract 4 , the instructor corrects the student by requesting an alternative action, in extract 5 , the instructor corrects by asking the student to stop an ongoing action. The extract is taken from a trial of reverse parking.

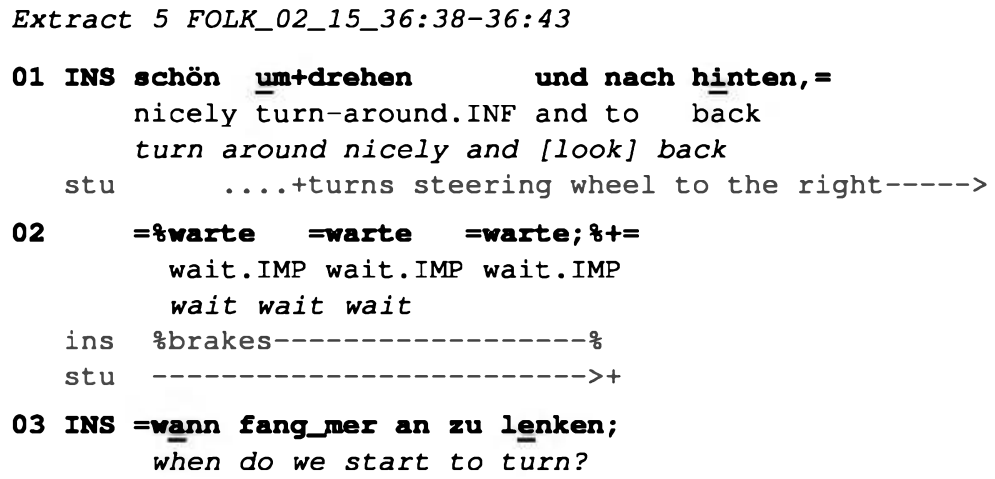

Using a deontic infinitive, the instructor reminds the student to look back (line 01). However, immediately after the instructor begins to formulate this request, the student starts to turn right, which may be occasioned by a misinterpretation of the upcoming request. ${ }^{4}$ The instructor brakes and makes the car stop, while requesting the student to stop (line 02). Latching the request to the prior TCU, fast delivery and repetition of the imperative request embody the urgency of the requested action (cf. Mondada, 2017), but also that the driver should stop the whole course of action (cf. Stivers, 2004). The three imperatives (which, however, amount to only one instruction) are bare, no argument is added, because the actions to be stopped - moving the car backwards and turning the steering wheel to the right - are salient to both participants and additionally made evident by the instructor operating the brake.

\subsection{Insisting on a prior instruction}

In extracts 4 and 5, we have already seen repeated uses of imperatives. Repetition may be immediately adjacent and fast (like in extract 5) so that it is rather a design feature contextualizing urgency. Repetition is also used to insist on 
the lingering relevance of a prior instruction, which either was not complied with or the student had stopped their compliant action too early. In extracts 4 and 5 , the prior instruction had already been formulated by an imperative. In other cases, imperatives are used to insist on the lingering relevance of an instruction that had been formulated by a declarative or a deontic infinitive. The sequential order thus is:

1. INS: instruction by declarative or deontic infinitive;

2. STU: failure to follow instruction (continuously); and

3. INS: imperative used to insist on compliance with prior instruction.

The reverse order of grammatical formats does not occur in the data. Extract 6 shows an example of a declarative instruction (line 01), which is repeated by an imperative (lines 06,08 ).

Extract 6 FAHR_02_15_34:24-34:38

01 INS: jetzt sguckste wieder nach hintten, i und lenkst fertig. Now look-you again to backwards and steer.2sg complete Now you look back again and complete turning

ins $\ldots . .$. o spoints to rear window------ $>$ o,$\ldots$,

stu $\quad \ldots \ldots+$ looks to rear window----- $\rightarrow$

$02(0.6)$

03 und zwar wohin?

and indeed where

and in fact where

04

$(0.2)+(2.3)$

stu $\quad--->+\ldots .$.

05

INS: wot soll dein auto, =

Where should your car

stu $\quad .+$ looks to the front window--------->

06

=guck mal nach [hin\#ten;]

Look. IMP PTCL to bäckwards

Just look backwards

07 STU:

[in \#die ] richtung.+

in this direction

\#Fig. 1

08

stu

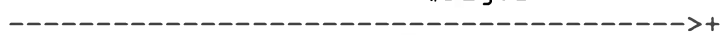

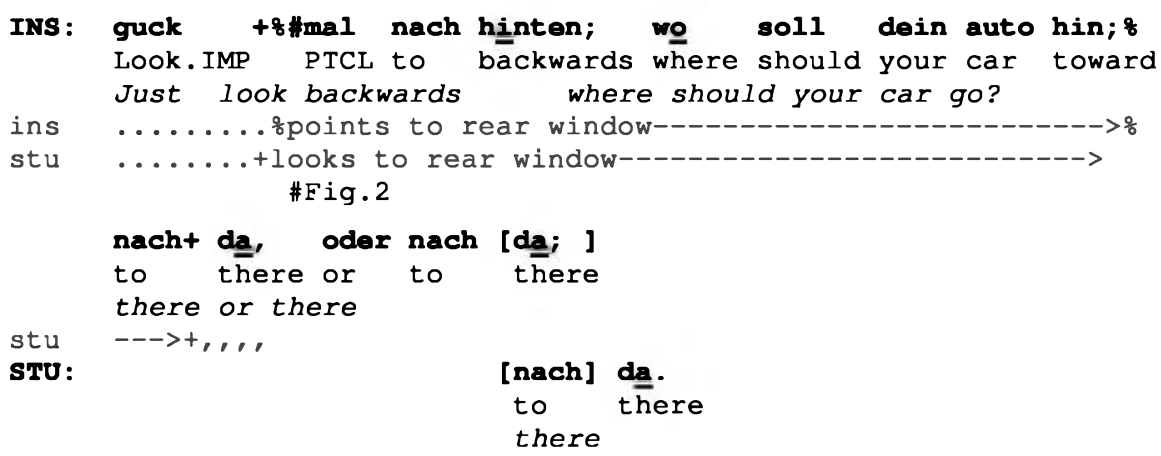

The teacher asks the student to look back while she reverses the car (line 01). The student complies (lines 01-04). However, when the instructor asks her whether the car has to move to the left or to the right (line 03), the student turns her head to the front again (lines 04-07, Figure 1). The instructor uses two imperative requests (lines 06-08) to insist on the continuing relevance of looking back, and the student complies again (lines 08-09, Figure 2). The student seemed to mistake the instructor's question in line 03 as a transition to a new action sequence, implying that the prior orientation to 


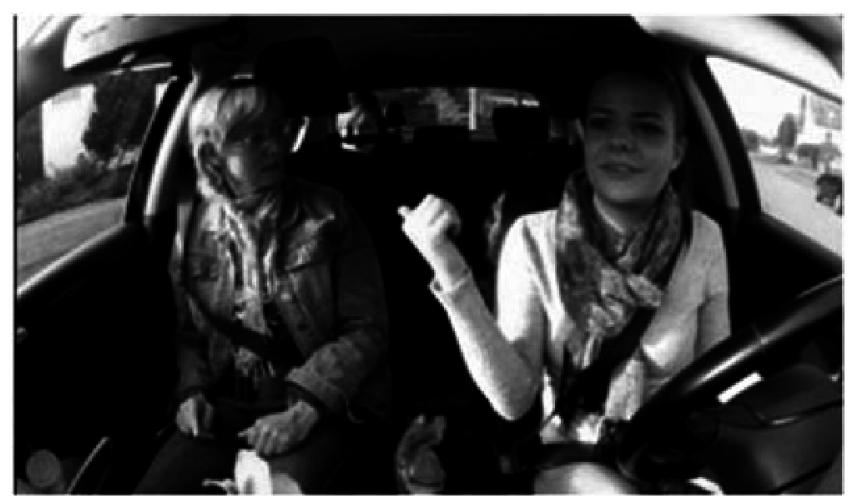

FIGURE 1 STU looks ahead and points to the right during INS first imperative request (Extract 6, line 07) [Colour figure can be viewed at wileyonlinelibrary.com]

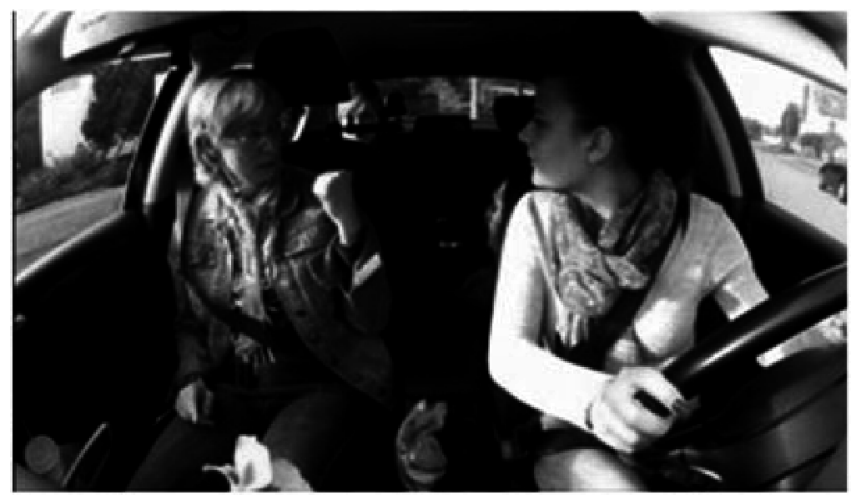

FIGURE 2 STU looks back during INS second imperative request accompanied by pointing (Extract 6, line 08) [Colour figure can be viewed at wileyonlinelibrary.com]

the backward movement of the car and thus to looking back was not relevant anymore. Instead, by insisting on the continuing relevance of the prior instruction, the instructor treats the prior orientation to backward driving and looking as the overarching project, in which the negotiation of how to direct the car laterally, is inserted and to be solved.

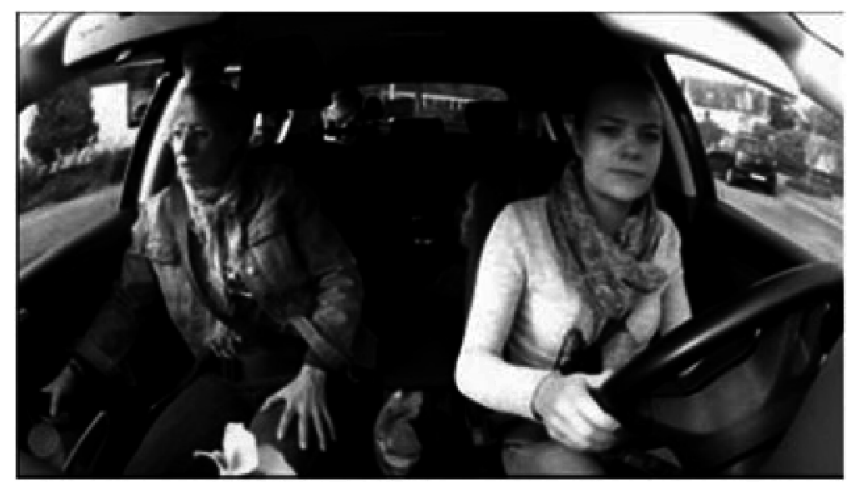

FIGURE 3 STU looks ahead (Extract 7, line 02) [Colour figure can be viewed at wileyonlinelibrary.com] 


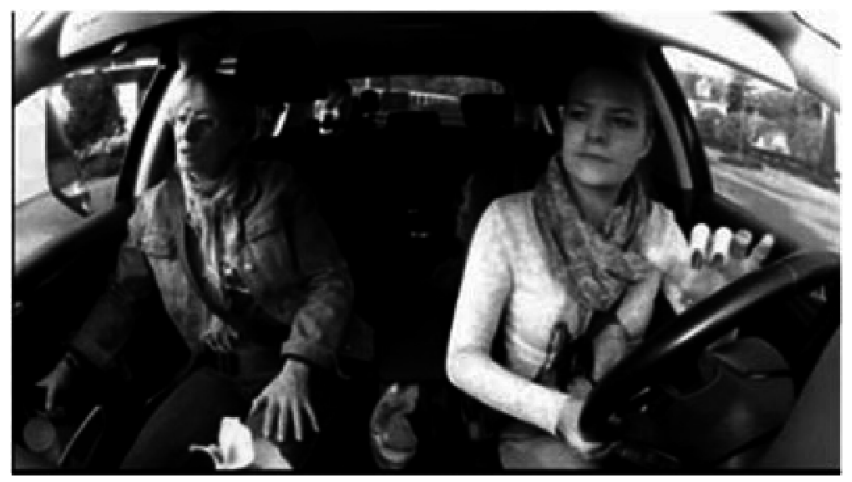

FIGURE 4 STU looks to the right while turning steering wheel to the right (Extract 7, line 05) [Colour figure can be viewed at wileyonlinelibrary.com]

Imperatives and deontic infinitives have very similar uses. However, imperatives can specifically be used to insist on the lingering relevance of a request which had been formulated before by a deontic infinitive. This is the case in extract 7: The instructor asks the student to look far ahead (line 02, Figure 3) with a deontic infinitive. The instruction is repeated with an imperative (line 05).

Extract 7 FAHR_02_15_36:04-36:15

01 INs un net un die ecke gucken

and not around the corner look. INF

and don't look around the corner

stu looks ahead----------------------->

02 sondern WEIT nach vorne gucken \#jetz;

but far to ahead look.INF now

but look far ahead now

\#Fig. 3

03

$(0.3)+(0.3)$

stu $---->+i n c r e a s i n g l y ~ l o o k s$ to the right---->

04 INS un lenken un lenken

and steer. INF and steer. INF

and steer and steer

05

(.) \#un guck nach vo:r+ne NICB tauf das auto; =

and look.IMP to ahead not at the car

and look ahead, not at the car

stu ------------------------>+......+looks ahead--->>

\#Fig. 4

06 INS =DA vorne hingucken; =und alles GRA:de machen;

there ahead look-at.INF and everything straight make. INF

look ahead there and get everything straight

The instructor accompanies the student's activity with a series of deontic infinitives (lines 01, 02, twice in 04, twice in 06), which guide the student through the process of reverse parking. Similar to extract 6 , the student ceases to follow the prior instruction to look ahead, when she starts to deal with a new task, here: turning the steering wheel to the right (lines 03-04, Figure 4). She looks to her right, presumably to make sure that she keeps the right distance to the car beside her. Using an imperative, the instructor, however, insists on her prior instruction that the student looks straight ahead (line 05). This instruction is the only one which retracts the instructional sequence, the imperative thus being used as a contrastive grammatical format highlighting that the student has failed to comply with a prior 
instruction correctly. The choice of the imperative may be seen to highlight agency and responsibility of the student, because in contrast to the deontic infinitive, the imperative morphologically encodes the 2 nd person. Afterwards, this instruction is repeated again, this time by another deontic infinitive (line 06).

\section{CONCLUSION}

Drawing on a corpus of driving lessons, this study contributes to research on the situated design of grammatical practices which are used for a class of actions, here: instructions. We have shown how declaratives and imperatives in German are linguistically adapted to different praxeological and participant-related environments of instruction. The following factors have proved to be relevant for the choice of declaratives vs. imperatives and for differences in complex (declarative) vs. minimal (imperative) argument structure:

- the interactional history of the type of instruction and the common ground: first instructions of a skill vs. later instructions;

- situational contingencies: planned instructions vs. instructions occasioned by emergent situational developments;

- the current ongoing driving action of the student: actions which run counter to instructors' expectations about correct performance;

- the instructional sequence: the position of the instruction within complex task-performances and with regard to prior instructions of the same actions;

- the turn-construction: the position of the instruction vis-à-vis another instruction,

- temporal requirements for the response: immediate/urgent response vs. no response in situ; and

- the movement of the car: instructions while the car is standing vs. during driving.

Declaratives used in first instructions, for task-setting and in post-trial discussions exhibit relatively complex syntax as compared to non-declarative formats used for instruction. In particular, they contain several arguments, which are mostly lexical, rather than pronominal, and sometimes adverbial clauses. The grammatical and lexical complexity of these instructions reflects that they formulate actions the recipient is not yet familiar with or cannot be taken to expect at the moment of their formulation, because they initiate a new joint project. In contrast to syntactically simpler formats, declarative instructions do not call for an immediate compliant action, but they may either describe how some task is to be solved in principle (4.1 and 4.3) or they formulate the endpoint of a complex series of actions (4.2). The declarative mode together with the relatively high degree of explicitness and descriptive detail lend these instructions a strong descriptive component which conveys not only that some action has to be performed but also how it is to be carried out.

For the largest part, imperative instructions respond to ongoing actions of the student or to their failure to produce an expected action (5.1-5.2). Since such corrective or insisting imperatives build on the student's current action or direct the student's attention to situational relevancies that are taken to be salient or unproblematically accessible to the recipient, they can do with minimal argument structure and mostly without any complements (cf. Zinken \& Deppermann, 2017). The focus is on the instructed action as such, but not on objects, instruments, directions, causes or consequences. This is in sharp contrast to the use of declaratives, but also to instructions without a verb which encode objects or directions by NP, N, ADV or PP (see e.g. extract 2). The brevity of imperatives, sometimes paired with fast delivery, supports their temporal design: They are especially useful for requesting actions which have to be complied with not only immediately, but urgently (Mondada, 2013, 2017). (Morpho-)syntax thus is adapted to temporal, coordinative properties of ongoing bodily action, car movement and changes in the environment. Another source for the minimal design of imperative instructions is that they mandate actions that already belong to the 
student's repertoire and can be carried out unproblematically. In contrast to declaratives, imperatives are not used to instruct new actions for the first time. Imperative instructions (like deontic infinitives) are reminders: their minimal design indexes the "known-in-principle and should-have-been-performed character" of the mandated action. Imperatives thus build on three factors which are reflexively related to each other: salient parameters of the interactional situation (objects, landmarks, events, recipient's current action), the shared interactional and learning history and already acquired understandings of the joint projects and task structures within which the local instructed action becomes relevant.

\section{ENDNOTES}

${ }^{1}$ In the following schema and in the transcripts in this paper, the instructor is always abbreviated as 'INS', the student as 'STU'.

${ }^{2}$ Concerning epistemic asymmetry see Heritage (2013), concerning deontic asymmetries see Stevanovic and Peräkylä (2012).

${ }^{3}$ German Gas geben may be conceived of as a transitive construction with the accusative argument Gas. However, mostly gasgeben is regarded as a compound verb. This is supported by the fact that its semantics is non-compositional.

${ }^{4}$ She may have understood umdrehen ("turn around") in the instruction in line 01 to be referring to the steering wheel, not to the student's head.

\section{ORCID}

Arnulf Deppermann D http://orcid.org/0000-0001-7575-8236

\section{REFERENCES}

Antaki, C., \& Kent, A. (2012). Telling people what to do (and, sometimes, why): contingency, entitlement and explanation in staff requests to adults with intellectual impairments. Journal of Pragmatics, 44(6-7), 876-889.

Blum-Kulka, S., House, J., \& Kasper, G. (1989). Cross-cultural pragmatics: Requests and apologies. Norwood, NJ: Ablex.

Broth, M., Cromdal, J., \& Levin, L. (2017). Starting out as a driver. Progression in instructed pedal work. In Å. Mäkitalo, P. Linell, \& R. Säljö (Eds.), Memory practices and learning - interactional, institutional and sociocultural perspectives (pp. 113-142). Charlotte, NC: Information Age.

Brown, P., \& Levinson, S. C. (1987). Politeness. Cambridge: Cambridge University Press.

Craven, A., \& Potter, J. (2010). Directives: Entitlement and contingency in action. Discourse Studies, 12(4), 419-442.

De Stefani, E., \& Gazin, A. (2014). Instructional sequences in driving lessons: Mobile participants and the temporal and sequential organization of actions. Journal of Pragmatics, 65, 63-79.

Deppermann, A. (2006). Deontische Infinitivkonstruktionen: Syntax, Semantik, Pragmatik und interaktionale Verwendung. In S. Günthner, \& W. Imo (Eds.), Konstruktionen in der Interaktion (pp. 239-262). Berlin: de Gruyter.

Deppermann, A. (2007). Grammatik und Semantik aus gesprächsanalytischer Sicht. Berlin: de Gruyter.

Deppermann, A. (2015). When recipient design fails: Egocentric turn-design of instructions in driving school lessons leading to breakdowns of intersubjectivity. Gesprächsforschung, 16, 63-101.

Deppermann, A. (2016). La définition comme action multimodale et contexte-sensitive : Définir pour instruire dans l'auto-école. Langages, 204(4), 83-101.

Deppermann, A. (forthcoming). Changes in turn design over interactional histories -the case of instructions in driving school lessons. In A. Deppermann, \& J. Streeck (Eds.), Temporalities and modalities. Amsterdam: Benjamins.

Drew, P., \& Couper-Kuhlen, E. (Eds.) (2014). Requesting in social interaction. Amsterdam: John Benjamins.

Goodwin, C. (2017). Co-operative action. Cambridge: Cambridge University Press.

Goodwin, M. H. (2006). Participation, affect, and trajectory in family directive/response sequences. Text and Talk, 26(4/5), 513-542.

Goodwin, M. H., \& Cekaite, A. (2013). Calibration in directive-response trajectories in family interactions. In Journal of Pragmatics, 46(1), 122-138.

Heritage, J. (2013). Epistemics in conversation. In J. Sidnell, \& T. Stivers (Eds.), Handbook of conversation analysis (pp. 370-394). New York: Wiley-Blackwell. 
Jefferson, G. (1990). List construction as a task and resource. In G. Psathas (Ed.), Interaction competence (pp. 63-92). Washington, DC: University Press of America.

Kendon, A. (1990). Conducting interaction. Cambridge: Cambridge University Press.

Lindwall, O., \& Ekström, A. (2012). Instruction-in-interaction: The teaching and learning of a manual skill. Human Studies, 35(1), 27-49.

Lindwall, O., Lymer, G., \& Greiffenhagen, C. (2015). The sequential analysis of instruction. In N. Markee (Ed.), The handbook of classroom discourse and interaction (pp. 142-157). Hoboken, NJ: Wiley.

Mondada, L. (2012). Talking and driving: Multiactivity in the car. Semiotica, 191(1/4), 223-256.

Mondada, L. (2013). Coordinating mobile action in real time: The timely organization of directives in video games. In P. Haddington, L. Mondada, \& M. Nevile (Eds.), Interaction and mobility (pp. 300-341). Berlin: de Gruyter.

Mondada, L. (2014). Instructions in the operating room: How the surgeon directs their assistant's hands. Discourse Studies, 16(2), 131-161.

Mondada, L. (2017). Imperatives in action. In E. Couper-Kuhlen, L. Raevaara, \& M.-L. Sorjonen (Eds.), Imperative turns at talk (pp. 65-101). Amsterdam: John Benjamins.

Rossi, G. (2012). Bilateral and unilateral requests: The use of imperatives and mi $x$ ? interrogatives in Italian. Discourse Processes, 49, 426-458.

Rossi, G. (2015) The request system in Italian interaction. Nijmegen: PhD Thesis, Radboud University.

Searle, J. R. (1979). Expression and meaning. Cambridge: Cambridge University Press.

Stevanovic, M., \& Peräkylä, A. (2012). Deontic authority in interaction: The right to announce, propose and decide. Research on Language and Social Interaction, 45(3), 297-321.

Stivers, T. (2004). 'No no no' and other types of multiple sayings in social interaction. Human Communication Research, 30(2), 260-293.

Vine, B. (2009). Directives at work: Exploring the contextual complexity of workplace directives. Journal of Pragmatics, 41(7), 1395-1405.

Zinken, J., \& Deppermann, A. (2017). A cline of visible commitment in the situated design of imperative turns. In E. CouperKuhlen, L. Raevaara, \& M.-L. Sorjonen (Eds.), Imperative turns at talk (pp. 27-63). Amsterdam: John Benjamins.

Zinken, J., \& Ogiermann, E. (2013). Responsibility and action: Object requests in English and Polish everyday interaction. Research on Language and Social Interaction, 46(3), 256-276. 